\title{
Programas de Alimentação para Matrizes Pesadas após o Pico de Postura, com Base em Modelos para Predizer a Exigência Energética ${ }^{1}$
}

\author{
Nilva Kazue Sakomura ${ }^{2}$, Andrea Luciana dos Santos ${ }^{3}$, Ednardo Rodrigues Freitas ${ }^{3,4}$, \\ Carlos Boa-Viagem Rabello ${ }^{3,5}$
}

\begin{abstract}
RESUMO - Este trabalho foi conduzido com o objetivo de avaliar o desempenho de matrizes pesadas, submetidas a diferentes programas de alimentação estabelecidos pela aplicação de modelos para predizer as exigências energéticas, após o pico de postura. O experimento foi conduzido no setor de avicultura da UNESP - Campus Jaboticabal, com duração de 84 dias (três períodos de 28 dias). Foram utilizadas 740 matrizes de corte Hubbard Hy-Yield e 80 machos Petterson, com 55 semanas de idade. O delineamento foi inteiramente casualizado, com quatro tratamentos e cinco repetições de 37 aves por repetição (box) e um modelo fatorial $4 \times 3$ (quatro tratamentos $\times$ três períodos). Os programas de alimentação avaliados foram: T1 - Fornecimento de ração de acordo com o padrão da linhagem (428 kcal/ave/dia de 55 a 66 semanas de idade); T2 - Redução semanal de energia (2 kcal de EM/ave em cada semana); T3 - Fornecimento de ração de acordo com o modelo de exigência de EM, UNESP (2000); e T4 - Fornecimento de ração de acordo com o modelo, NRC (1994). O programa de alimentação com redução semanal de energia foi adequado para manter os desempenhos produtivo e reprodutivo das aves, indicando a possibilidade de redução de $2 \mathrm{kcal} / \mathrm{ave} / \mathrm{dia}$, em cada semana, na alimentação de matrizes pesadas após 55 semanas de idade. Os modelos UNESP e NRC proporcionaram estimativas mais elevadas das exigências energéticas que o modelo padrão, provavelmente em decorrência do ganho de peso das matrizes, que esteve acima do recomendado para a linhagem, promovendo maiores exigências de energia para mantença.
\end{abstract}

Palavras-chave: alimentação de matrizes pesadas, desempenhos produtivo e reprodutivo, exigências de energia metabolizável

\section{Feeding Programs for Broiler Breeder Hens after Peak Production Based on Models to Predict Energy Requirements}

\begin{abstract}
This research was carried out to evaluate the performance of broiler breeder hens submitted to different feeding programs applying models to predict the metabolizable energy requirements after peak production. The experiment was conducted during 84 days (three periods of 28 days), at the Sao Paulo State University - Jaboticabal. Seven hundred and forty female broiler breeders Hubbard Hy-Yield, and eighty males Petterson 55-week old were assigned to a randomized design with four treatments and five replicates of 37 birds (box), and a factorial model $4 \times 3$ (four treatments and three periods). The feeding programs evaluated were: T1 - feeding according to the lineage recommendation ( $428 \mathrm{kcal} / \mathrm{bird} /$ day from 55 to 66 -weeks old); T2 - energy reduction ( $2 \mathrm{kcal} / \mathrm{bird} / \mathrm{day}$ for each week); T3 - feeding according to UNESP (2000) model; T4 - feeding according to NRC (1994) Model. The feeding program with weekly energy reduction was suitable to maintain the productive and reproductive performance of the birds, indicating the possibility of reducing $2 \mathrm{kcal} / \mathrm{bird} / \mathrm{day}$, at each week, in broiler breeders fed after 55 weeks of age. The UNESP and NRC models promoted higher energy intakes than the lineage recommendation, probably due to the body weight of breeders, that were above the recommended for lineage, providing higher energy requirements of maintenance.
\end{abstract}

Key Words: broiler breeders feeding, metabolizable energy requirements, productive and reproductive performance

\section{Introdução}

A nutrição de matrizes pesadas necessita de constante avaliação, pois influencia fortemente a produção de ovos e pintos e também tem efeito direto na qualidade dos pintos de um dia e, por conseqüência, no desempenho e na uniformidade final dos lotes de frangos de corte.
As matrizes de corte tendem a consumir em excesso, quando alimentadas ad libitum além de suas necessidades energéticas para produção e manutenção. O excesso no consumo de energia é predominantemente armazenado como gordura, que resulta gradualmente em incremento do peso corporal e redução da fertilidade, eclodibilidade e produção de

\footnotetext{
1 Parte do projeto temático financiado pela FAPESP.

2 Professora do Departamento de Zootecnia - FCAV/UNESP - Jaboticabal (sakomura@fcav.unesp.br). Bolsista CNPq.

3 Pós-graduandos em Zootecnia pela FCAV/UNESP - Jaboticabal.

4 Endereço atual: Departamento de Zootecnia - CCA/UFC - Fortaleza.

5 Endereço atual: Departamento de Zootecnia/UFRPE - Recife.
} 
ovos. Com base nestes fatos, as recomendações de alimentação contidas nos manuais fornecidos pelos produtores de matrizes são expressas em consumo diário de nutrientes (Pearson \& Herron, 1981).

A prática de aumentar a quantidade de alimento para matrizes até o pico de produção é indiscutivelmente a mais aceita para obtenção de elevado índice de produção. Muitos criadores valorizam a necessidade de alto pico de produção de ovos e, algumas vezes, aumentam ou mantêm altas quantidades de ração, simplesmente para atingirem incremento de 0,1 a $0,5 \%$ no pico de produção de ovos. Em consequiência, obtêm-se custo adicional de alimentação e excessivo ganho de peso nas reprodutoras, prejudicando seu desempenho reprodutivo (Lewis, 1996).

Com o intuito de prevenir a obesidade nas aves e o concomitante declínio na produção, eclodibilidade e fertilidade dos ovos, a redução da quantidade de ração após o pico de produção é fundamental. Entretanto, diversos autores (Pym \& Dillon, 1974; Chaney \& Fuller, 1975; Blair et al., 1976) afirmam que, durante a fase de produção, a restrição alimentar deve ser aplicada cuidadosamente, devido à necessidade de manter a produção de ovos, pois restrição excessiva pode acarretar queda de postura.

A alimentação de reprodutoras pesadas na fase de produção, normalmente, baseia-se na produção de ovos. Entretanto, há outros fatores que devem ser considerados para estabelecer a quantidade de energia a ser fornecida, como temperatura, peso corporal e ganho de peso. Alguns modelos de predição das exigências energéticas recomendas pelo NRC (1994) e por Sakomura et al. (1993) consideram estes fatores, que afetam as exigências e permitem estabelecer um programa de alimentação mais adequado.

Em trabalho de tese realizado na UNESP Jaboticabal (Rabello, 2000a), foi desenvolvido um modelo de predição das exigências de energia metabolizável para matrizes na fase de produção, $\mathrm{EM}=\mathrm{P}^{0,75}\left(192,76-6,32 \cdot \mathrm{T}+0,12 \cdot \mathrm{T}^{2}\right)+7,62 \cdot \mathrm{G}+$ 2,40.MO, em que $\mathrm{EM}=$ exigência de energia metabolizável (kcal/ave/dia), $\mathrm{P}=$ peso corporal $(\mathrm{kg})$, $\mathrm{T}=$ temperatura ambiente $\left({ }^{\circ} \mathrm{C}\right), \mathrm{G}=$ ganho de peso (g) e $\mathrm{MO}=$ massa de ovos produzida $(\mathrm{g})$. Este modelo foi desenvolvido utilizando-se o método fatorial, que se baseia na divisão das exigências para mantença, produção e/ou crescimento.

Objetivou-se, com o presente trabalho, avaliar o desempenho de matrizes pesadas submetidas a programas de alimentação estabelecidos pela aplicação de modelos para predizer as exigências energéticas, após o pico de postura.

\section{Material e Métodos}

O experimento foi realizado no galpão experimental do Setor de Reprodução de Aves do Departamento de Zootecnia da UNESP - Campus Jaboticabal, no período de abril a junho de 2000, com duração de 84 dias (três períodos de 28 dias).

Foram alojados em boxes $(3,90 \times 3,35 \mathrm{~m}) 740$ matrizes de corte Hubbard Hy-Yield e 80 machos Petterson, com 55 semanas de idade, sendo 37 fêmeas e quatro machos por box. Cada box foi equipado com quatro comedouros tubulares para fêmeas e grade de restrição para machos, um comedouro tubular para os machos, instalado na altura dos mesmos, dois bebedouros pendulares e dois ninhos de madeira com seis bocas cada.

Antes de iniciar o experimento, as aves foram pesadas individualmente e distribuídas de modo a obter pesos uniformes entre as parcelas experimentais. A produção de ovos de cada parcela também foi controlada. Com base nessas informações, as parcelas foram sorteadas e distribuídas de modo a manter a uniformidade entre os tratamentos.

O delineamento experimental utilizado foi inteiramente casualizado, para as características de desempenho reprodutivo, com quatro tratamentos e cinco repetições, sendo 37 aves por repetição (box) e um modelo fatorial $4 \times 3$ (quatro tratamentos e três períodos) para as características produtivas.

Os tratamentos consistiram no fornecimento de ração de acordo com quatro programas de alimentação: T1 - fornecimento de ração de acordo com o padrão da linhagem (428 kcal/ave/dia de 55 a 66 semanas de idade); T2 - redução semanal de energia ( $2 \mathrm{kcal}$ de EM/ave/dia); T3 - fornecimento de ração de acordo com o modelo de exigência de EM, UNESP (2000): $\mathrm{EM}=\mathrm{P}^{0,75}\left(192,76-6,32 \cdot \mathrm{T}+0,12 \cdot \mathrm{T}^{2}\right)+7,62 \cdot \mathrm{G}+$ 2,40.MO; e T4 - fornecimento de ração de acordo com o modelo NRC (1994): $\mathrm{EM}=\mathrm{P}^{0,75}(173-1,95 . \mathrm{T})+$ 5,5.G + 2,07.O, em que EM = exigência de energia metabolizável (kcal/ave/dia), $\mathrm{P}=$ peso corporal $(\mathrm{kg})$, $\mathrm{T}=$ temperatura ambiente $\left({ }^{\circ} \mathrm{C}\right), \mathrm{G}=$ ganho de peso $(\mathrm{g})$ e $\mathrm{O}=$ massa do ovo $(\mathrm{g})$.

A alimentação das fêmeas foi feita de acordo com cada tratamento, fornecendo-se uma ração separada para os machos; a água foi fornecida à vontade para as aves.

R. Bras. Zootec., v.33, n.5, p.1197-1208, 2004 
As quantidades de ração fornecida pelos tratamentos 3 e 4 foram estabelecidas com base nas exigências determinadas pelos modelos de predição, considerando-se o teor de energia na ração.

Para determinar as exigências de EM diárias, foram aplicados nos modelos os dados médios de peso corporal, ganho de peso e produção de ovos de cada parcela experimental e a temperatura média ambiente medida diariamente. As exigências foram calculadas semanalmente, em função do peso corporal, da massa de ovos e do ganho de peso previstos para a semana.

Os registros da temperatura ambiente foram obtidos por meio de termohigrógrafo posicionado no nível das aves (Tabela 1). A temperatura média aplicada no fator de correção da temperatura dos modelos foi baseada na temperatura média do dia anterior e calculada de acordo com o padrão do Instituto Nacional de Meteorologia (INMET-Brasília), conforme a fórmula abaixo:

\section{Temperatura média $\left({ }^{\circ} \mathrm{C}\right)=(\mathrm{T} 9 \mathrm{~h}+$ Tmín. + Tmáx. $+2 \mathrm{~T} 21 \mathrm{~h}) / 5$}

em que $\mathrm{T} 9 \mathrm{~h}=$ temperatura às $9 \mathrm{~h}\left({ }^{\circ} \mathrm{C}\right)$; Tmín. $=$ temperatura mínima $\left({ }^{\circ} \mathrm{C}\right)$; Tmáx. = temperatura máxima $\left({ }^{\circ} \mathrm{C}\right) ; \mathrm{T} 21 \mathrm{~h}=$ temperatura às $21 \mathrm{~h}\left({ }^{\circ} \mathrm{C}\right)$.

As rações foram formuladas de forma que a ingestão diária de nutrientes, com exceção da EM, fosse a mesma entre os tratamentos, sendo que os níveis destes nutrientes foram estabelecidos de acordo com as recomendações do manual da linhagem.

A cada ciclo de 28 dias, foram avaliados os seguintes parâmetros: produção de ovos (\%/ave/dia), peso médio dos ovos (g), massa de ovos (g), consumo de ração (g), consumo de energia (kcal/ave/dia), conversão alimentar (g de ração/g de ovo produzida) e conversão energética (kcal EM/g de ovo produzida).

Ao final do experimento (às 66 semanas de idade), todas as aves da parcela foram pesadas para se determinar o ganho de peso no período de 55 a 66 semanas de idade.

$\mathrm{Na} 63^{\text {a }}$ semana de idade, foram incubados em média 135 ovos por parcela experimental. Os ovos foram coletados, selecionados, desinfetados e armazenados em sala climatizada até o momento de serem incubados. Para incubação, foram utilizadas máquinas de incubação e nascimento da marca Rooster Ltda, com capacidade para 8.400 ovos. Os parâmetros avaliados foram:

Taxa de eclosão (\%): calculada pela divisão entre o número de pintos nascidos e o número de ovos incubados, multiplicado por 100.

Eclodibilidade (\%): calculada pela divisão entre o número de pintos nascidos e o número de ovos férteis incubados, multiplicado por 100.

Fertilidade (\%): calculada pela divisão entre o número de ovos férteis e o número de ovos incubados.

Peso médio dos pintos ao nascer: refere-se ao peso de todos os pintos dividido pelo número total de pintos total.

As análises estatísticas foram realizadas utilizando-se o procedimento GLM do SAS (1996). As características de desempenho produtivo foram analisadas segundo um esquema fatorial $4 \times 3$ (quatro tratamentos $\mathrm{x}$ três períodos) e as características de desempenho reprodutivo, segundo um modelo inteiramente cazualizado. As diferenças entre as médias dos tratamentos para as variáveis foram detectadas utilizando-se o teste Tukey, a $5 \%$ de probabilidade.

Tabela 1 - Temperatura e umidade relativa observadas nos períodos experimentais Table1 - Temperature and relative humidity observed in the experimental periods

\begin{tabular}{cccccccc}
\hline & & \multicolumn{3}{c}{$\begin{array}{c}\text { Temperatura média }\left({ }^{\circ} \mathrm{C}\right) \\
\text { Pean temperature }\left({ }^{\circ} \mathrm{C}\right)\end{array}$} & & \multicolumn{2}{c}{$\begin{array}{c}\text { Umidade relativa (\%) } \\
\text { Relative humidity (\%) }\end{array}$} \\
\cline { 3 - 5 } $\begin{array}{c}\text { Mês } \\
\text { Month }\end{array}$ & Period & $\begin{array}{c}\text { Mínima } \\
\text { Minimum }\end{array}$ & $\begin{array}{c}\text { Máxima } \\
\text { Maximum }\end{array}$ & $\begin{array}{c}\text { Média } \\
\text { Mean }\end{array}$ & & $\begin{array}{c}\text { Mínima } \\
\text { Minimum }\end{array}$ & $\begin{array}{c}\text { Máxima } \\
\text { Maximum }\end{array}$ \\
\hline $\begin{array}{c}\text { Abril } \\
\text { April }\end{array}$ & 1 & 16,90 & 28,90 & 22,10 & & 33,40 & 80,50 \\
$\begin{array}{c}\text { Maio } \\
\text { May }\end{array}$ & 2 & 13,70 & 26,40 & 19,10 & & 32,20 & 81,30 \\
$\begin{array}{c}\text { Junho } \\
\text { June }\end{array}$ & 3 & 12,90 & 26,40 & 18,80 & & 29,20 & 76,70 \\
\hline
\end{tabular}

R. Bras. Zootec., v.33, n.5, p.1197-1208, 2004 


\section{Resultados e Discussão}

Os consumos de ração e de energia nos diferentes períodos são apresentados na Tabela 2. Houve interação significativa entre tratamentos e períodos para essas variáveis.

Como já previa o próprio programa de alimentação proposto pelo manual de linhagem, as aves submetidas a esse programa receberam a mesma quantidade diária de ração (149,13 g) e energia (428 kcal/ave/dia), durante todo o período experimental. O programa de alimentação com redução semanal de $2 \mathrm{kcal} / \mathrm{ave} / \mathrm{dia}$ de energia metabolizável proporcionou diminuição na quantidade de ração consumida, em relação ao grupo padrão, de 1,04; 3,83 e 6,62 g, e de energia de 3; 11 e $19 \mathrm{kcal} \mathrm{EM} / \mathrm{ave} /$ dia no primeiro, segundo e terceiro períodos, respectivamente, sendo que, somente nos dois últimos, a diferença foi significativa.
A ingestão média de energia pelas aves alimentadas com o programa de redução semanal de energia (417 kcal EM/ave/dia) foi próxima à preconizada por Waldroup et al. (1976), com base em um modelo para estimar as exigências de reprodutoras pesadas a partir de 50 semanas de idade, a $24^{\circ} \mathrm{C}$.

$\mathrm{O}$ programa de alimentação, segundo o modelo NRC (1994), promoveu consumos de ração e energia superiores aos demais programas, em todos os períodos, resultando na maior ingestão média de ração e de energia durante o experimento.

A partir do 2ㅇ período (59-62 semanas de idade), as aves alimentadas segundo o modelo UNESP (2000) consumiram maior quantidade de ração e de energia em relação às alimentadas segundo o padrão da linhagem e o programa com redução semanal de energia.

O modelo NRC (1994) nos três períodos e o UNESP (2000) a partir do $2 \underline{0}$ período estimaram

Tabela 2 - Consumos de ração (g/ave/dia) e de energia (kcal EM/ave/dia) de matrizes pesadas submetidas a diferentes programas de alimentação, nos períodos de 55-58, 59-62, 63-66 e 55-66 semanas

Table 2 - Feed intake (g/bird/day) and energy intake ( $k c a l$ ME/bird/day) for broiler breeder submitted to different feeding programs in periods of 55-58, 59-62, 63-66 and 55-66 weeks

\begin{tabular}{|c|c|c|c|c|}
\hline \multirow[t]{2}{*}{$\begin{array}{l}\text { Programas alimentares } \\
\text { Feeding programs }\end{array}$} & \multicolumn{4}{|c|}{$\begin{array}{l}\text { Períodos (Semanas) } \\
\text { Periods (Weeks) }\end{array}$} \\
\hline & $55-58$ & $59-62$ & $63-66$ & $55-66$ \\
\hline & \multicolumn{4}{|c|}{$\begin{array}{l}\text { Consumo de ração (g/ave/dia) } \\
\text { Feed intake (g/bird/day) }\end{array}$} \\
\hline Padrão & $149,13^{\mathrm{Ba}}$ & $149,13^{\mathrm{Ca}}$ & $149,13^{\mathrm{Ca}}$ & 149,13 \\
\hline $\begin{array}{l}\text { Control } \\
\text { Redução de energia semanal } \\
\text { Weekly energy reduction }\end{array}$ & $148,09^{\mathrm{Ba}}$ & $145,30^{\mathrm{Cab}}$ & $142,51^{\mathrm{Db}}$ & 145,30 \\
\hline Modelo UNESP(2000) & $150,64^{\mathrm{Bb}}$ & $155,84^{\mathrm{Ba}}$ & $156,44^{\mathrm{Ba}}$ & 154,30 \\
\hline $\begin{array}{l}\text { Model-UNESP (2000) } \\
\text { Modelo NRC (1994) } \\
\text { Model-NRC (1994) }\end{array}$ & $161,35^{\mathrm{Ab}}$ & $170,80^{\mathrm{Aa}}$ & $173,78^{\mathrm{Aa}}$ & 168,64 \\
\hline Média (Mean) & 152,30 & 155,27 & 155,46 & 154,82 \\
\hline \multirow[t]{2}{*}{$\mathrm{CV}(\%)$} & 1,33 & & & \\
\hline & \multicolumn{4}{|c|}{$\begin{array}{c}\text { Consumo de energia (kcal EM/ave/dia) } \\
\text { Energy intake ( } k \text { cal ME/bird/day) }\end{array}$} \\
\hline $\begin{array}{l}\text { Padrão } \\
\text { Control }\end{array}$ & $428,00^{\mathrm{Ba}}$ & $428,00^{\mathrm{Ca}}$ & $428,00^{\mathrm{Ca}}$ & 428,00 \\
\hline $\begin{array}{l}\text { Redução de energia semanal } \\
\text { Weekly energy reduction }\end{array}$ & $425,00^{\mathrm{Ba}}$ & $417,00^{\mathrm{Cab}}$ & $409,00^{\mathrm{Db}}$ & 417,00 \\
\hline $\begin{array}{l}\text { Modelo UNESP }(2000) \\
\text { Model - UNESP (2000) }\end{array}$ & $432,35^{\mathrm{Bb}}$ & $447,28^{\mathrm{Ba}}$ & $448,97^{\mathrm{Ba}}$ & 442,86 \\
\hline $\begin{array}{l}\text { Modelo-NRC (1994) } \\
\text { Model-NRC (1994) }\end{array}$ & $463,08^{\mathrm{Ab}}$ & $490,19^{\mathrm{Aa}}$ & $498,74^{\mathrm{Aa}}$ & 484,00 \\
\hline Média (Mean) & 437,74 & 447,12 & 448,13 & 444,33 \\
\hline $\mathrm{CV}(\%)$ & \multicolumn{4}{|c|}{1,33} \\
\hline
\end{tabular}

Médias seguidas de diferentes letras maiúsculas na coluna e minúsculas na linha diferem $(P<0,05)$ estatisticamente pelo teste Tukey.

Means followed by different capital letter in the column and small letter in the line differ $(P<.05)$ by Tukey test.

\section{R. Bras. Zootec., v.33, n.5, p.1197-1208, 2004}


consumos de ração e de energia mais elevados que o proposto pelo manual da linhagem, o que resultou em valores médios mais elevados no período total do experimento. Considerando esses dados, as aves alimentadas com base no modelo UNESP (2000) consumiram, em média, 5,17 g/ave/dia de ração e $14,86 \mathrm{kcal} \mathrm{EM} /$ ave/dia a mais em relação ao grupo alimentado de acordo com o manual (padrão). Entretanto, as aves alimentadas conforme o modelo NRC (1994) consumiram 19,51 g/ave/dia e $56 \mathrm{kcal} /$ ave/dia a mais que as aves alimentadas de acordo com o manual da linhagem.

Exceto para aves submetidas ao programa de alimentação de acordo com o manual da linhagem, que fixou a ingestão de energia e, conseqüentemente, a de ração, observa-se que, para os demais programas, houve variação na ingestão de ração e de energia ao longo dos períodos. Esses resultados são impostos pela característica de cada programa para determinar a quantidade de energia adequada para as aves, alterando a quantidade de ração oferecida.

No programa com redução semanal, a cada semana, as aves recebiam $2 \mathrm{kcal}$ a menos de energia, reduzindo-se a quantidade de ração oferecida para as aves ou utilizando-se uma ração menos energética. Entretanto, para os modelos NRC e UNESP, as alterações ocorrerão diariamente, em função da temperatura, e semanalmente, em razão de mudanças na previsão do ganho de peso e da redução da massa de ovos produzida para adequar as estimativas do modelo, em função dos resultados de cada parcela.

As maiores estimativas para o fornecimento de energia por um modelo, algumas vezes, resultou em maior ingestão de ração, em razão do aumento da quantidade de ração oferecida as aves para atender às exigências propostas. Isso pode ser observado na aplicação do programa de alimentação com base no modelo NRC (1994), em que a estimativa da quantidade de energia foi maior que a requerida pelas aves, resultando em maior ingestão de alimento em relação aos demais tratamentos.

Os resultados de produção, peso e massa de ovos observados conforme os programas de alimentação são apresentados na Tabela 3. A análise estatística dos dados mostrou que não houve interação entre os tratamentos e o período.

A redução semanal de energia não afetou a produção, indicando que a quantidade de energia fornecida às aves submetidas a esse programa de alimentação foi suficiente para manter a produção de ovos.
O peso dos ovos (Tabela 3) foi influenciado significativamente pelos programas de alimentação e períodos. Observou-se que, à medida que as aves envelheceram, o peso dos ovos aumentou, independentemente do programa de alimentação, o que já era esperado, em virtude do maior desenvolvimento corporal das aves, com o avançar da idade, e da redução na produção de ovos.

Em relação aos programas de alimentação, a diferença entre o peso dos ovos ficou restrita aos resultados obtidos com o programa de redução semanal de energia em relação aos do programa com o modelo NRC (1994).

Esses resultados podem ser atribuídos à maior diferença na ingestão de energia das aves alimentadas com estes programas, uma vez que, desde o modelo do NRC (1994), consumiram mais ração e, conseqüentemente, mais energia.

Alguns autores (Kuana, 1986; Sakomura et al., 1995; Attia et al., 1995; Rabello et al., 2000b) observaram que os diferentes fornecimentos de energia para matrizes pesadas não influenciaram o peso dos ovos. Por outro lado, Bornstein et al. (1979), Macdaniel \& Brake (1981), Pearson \& Herron (1981 e 1982b) e Spratt \& Leeson (1987) encontraram aumento no peso dos ovos, quando utilizaram níveis de energia mais elevados.

A massa de ovos não foi influenciada pelos programas de alimentação. Entretanto, houve redução com o avanço da idade. Essa variável é calculada em função do número de ovos produzido e do peso desses ovos. Embora o peso dos ovos tenha aumentado com a idade, a produção diminuiu. Dessa forma, a redução na produção influiu nos resultados obtidos para a massa de ovos.

A análise dos dados mostrou que não houve interação entre os programas de alimentação e os períodos para conversão alimentar e energética (Tabela 4), mas houve efeito significativo dos programas e dos períodos. Com o avançar da idade, as aves apresentaram pior conversão alimentar e energética, independentemente do programa de alimentação. Esses resultados podem ser atribuídos à redução na massa de ovos, com o envelhecimento (Tabela 3), uma vez que esta variável é calculada em função da massa de ovos produzida.

Os piores resultados de conversão alimentar e energética foram apresentados pelo modelo NRC (1994), com exceção do 2o período, em que o modelo NRC não diferiu estatisticamente do modelo UNESP (2000), para as conversões alimentar e energética.

\section{R. Bras. Zootec., v.33, n.5, p.1197-1208, 2004}


O peso das aves no início e final do experimento, bem como o ganho de peso durante o período experimental, são apresentados na Tabela 5. A análise estatística para ganho de peso mostrou que as aves alimentadas segundo o modelo NRC (1994) apresentaram maior ganho de peso em relação às submetidas aos demais tratamentos. Esse ganho foi
181,256 e $126 \%$ superior ao apresentado pelas aves submetidas aos programas de alimentação padrão, redução de energia semanal e UNESP (2000), respectivamente.

O ganho de peso obtido durante todo o experimento foi de 2,74; 2,16; 3,40 e 7,67 g/ave/dia para os programas de alimentação padrão, redução

Tabela 3 - Porcentagem de postura (ave/dia), peso de ovos (g) e massa de ovos (g/ave/dia) de matrizes pesadas submetidas a diferentes programas de alimentação nos períodos de 55 a 58, 59 a 62, 63 a 66 e de 55 a 66 semanas de idade

Table 3 - Egg producion (\% bird/day), egg weight $(g)$ and egg mass ( $g /$ bird/day) for broilers breeders submitted to different feeding programs, from 55-58, 59-62, 63-66, and 55-66 weeks

\begin{tabular}{|c|c|c|c|c|}
\hline \multirow[t]{2}{*}{$\begin{array}{l}\text { Programas alimentares } \\
\text { Feeding programs }\end{array}$} & \multicolumn{4}{|c|}{$\begin{array}{c}\text { Períodos (Semanas) } \\
\text { Periods (Weeks) }\end{array}$} \\
\hline & $55-58$ & $59-62$ & $63-66$ & $55-66$ \\
\hline & \multicolumn{4}{|c|}{$\begin{array}{c}\text { Porcentagem de postura }(\%) \\
\text { Egg production }(\%)\end{array}$} \\
\hline Padrão & 69,23 & 62,81 & 59,83 & 63,96 \\
\hline Control & & & & \\
\hline $\begin{array}{l}\text { Redução de energia semanal } \\
\text { Weekly energy reduction }\end{array}$ & 68,64 & 62,70 & 59,02 & 63,46 \\
\hline Modelo UNESP (2000) & 69,49 & 61,99 & 59,26 & 63,58 \\
\hline Model-UNESP (2000) & & & & \\
\hline Modelo NRC (1994) & 66,06 & 61,34 & 56,53 & 61,31 \\
\hline Model - NRC (1994) & & & & \\
\hline Média (Mean) & $68,34^{\mathrm{a}}$ & $62,19^{\mathrm{b}}$ & $58,64^{\mathrm{c}}$ & 63,06 \\
\hline \multirow[t]{2}{*}{$\mathrm{CV}(\%)$} & 6,44 & & & \\
\hline & \multicolumn{4}{|c|}{$\begin{array}{c}\text { Peso dos ovos }(\mathrm{g}) \\
\text { Egg weight }(g)\end{array}$} \\
\hline Padrão & 68,24 & 69,57 & 70,35 & $69,39^{\mathrm{AB}}$ \\
\hline $\begin{array}{l}\text { Control } \\
\text { Redução de energia semanal } \\
\text { Weekly energy reduction }\end{array}$ & 68,08 & 69,80 & 70,58 & $69,48^{\mathrm{B}}$ \\
\hline Modelo UNESP (2000) & 67,77 & 69,35 & 70,27 & $69,13^{\mathrm{AB}}$ \\
\hline $\begin{array}{l}\text { Model - UNESP }(2000) \\
\text { Modelo NRC (1994) } \\
\text { Model-NRC (1994) }\end{array}$ & 68,42 & 70,41 & 71,35 & $70,06^{\mathrm{A}}$ \\
\hline Média (Mean) & $68,13^{a}$ & $69,78^{b}$ & $70,64^{\mathrm{c}}$ & 69,52 \\
\hline \multirow[t]{2}{*}{$\mathrm{CV}(\%)$} & 0,97 & & & \\
\hline & \multicolumn{4}{|c|}{$\begin{array}{l}\text { Massa de ovo (g/ave/dia) } \\
\text { Egg mass (g/bird/day) }\end{array}$} \\
\hline Padrão & 47,24 & 43,70 & 42,09 & 44,34 \\
\hline $\begin{array}{l}\text { Control } \\
\text { Redução de energia semanal } \\
\text { Weekly energy redution }\end{array}$ & 46,71 & 43,75 & 41,62 & 44,03 \\
\hline $\begin{array}{l}\text { Modelo UNESP }(2000) \\
\text { Model-UNESP }(2000)\end{array}$ & 47,08 & 42,96 & 41,63 & 43,89 \\
\hline Modelo NRC (1994) & 45,18 & 43,16 & 40,32 & 42,89 \\
\hline Model-NRC (1994) & & & & \\
\hline Média (Mean) & 46,55 & 43,37 & 41,41 & 43,77 \\
\hline $\mathrm{CV}(\%)$ & & 6,27 & & \\
\hline
\end{tabular}

Médias seguidas de diferentes letras maiúsculas na coluna e minúsculas na linha diferem $(\mathrm{P}<0,05)$ estatisticamente pelo teste Tukey.

Means followed by different capital letter in the column and small letter in the line differ $(P<.05)$ by Tukey test. 
de energia, modelos UNESP (2000) e NRC (1994), respectivamente.

Avaliando o peso das aves durante cada semana do experimento (Figura 1), observa-se que o peso médio inicial ( 55 semanas) foi similar para todos os tratamentos, mas, com o avanço da idade, as aves alimentadas, segundo o modelo NRC (1994), apresentaram os maiores pesos durante todo o período experimental. Com o programa estabelecido pelo modelo UNESP (2000), somente a partir de 61 semanas de idade, as aves iniciaram ganho de peso excessivo, quando comparados aos programas recomendados segundo padrão da linhagem e com redução de energia semanal.

As aves submetidas ao programa de alimentação com redução de energia semanal apresentaram ganho de peso próximo ao obtido com o programa de alimentação recomendado para a linhagem, indicando que a quantidade de energia fornecida foi suficiente para manter a produção e proporcionar ganho de peso satisfatório.

Para estabelecer o padrão de alimentação semanal das aves alimentadas com base nos modelos, foram previstos o ganho de peso das aves a cada semana. Comparando-se os dados de ganho de peso obtido em relação aos valores previstos (Tabela 6), verificou-se que os programas de alimentação proporcionaram ganhos de peso superiores aos previstos, com exceção do segundo período, quando os programas de alimentação padrão e com redução de energia

Tabela 4 - Conversão alimentar (g ração/g de ovo) e conversão energética (kcal EM/g de ovo) de matrizes pesadas submetidas a diferentes programas de alimentação, nos períodos de 55 a 58, 59 a 62, 63 a 66 e 55 a 66 semanas de idade

Table 4 - Feed conversion (g feed/g egg) and energy conversion ( $\mathrm{kcal} \mathrm{ME} / \mathrm{g}$ egg) for broilers breeders submitted to different feeding programs from 55-58, 59-62, 63-66 and 55-66 weeks

\begin{tabular}{lcccc}
\hline \multicolumn{1}{c}{$\begin{array}{c}\text { Programas alimentares } \\
\text { Feeding programs }\end{array}$} & \multicolumn{4}{c}{$\begin{array}{c}\text { Períodos (Semanas) } \\
\text { Periods }(\text { Weeks })\end{array}$} \\
\cline { 2 - 5 } & $55-58$ & $59-62$ & $63-66$ & $55-66$ \\
\hline \multicolumn{4}{c}{ Corcentagem de postura $(\%)$} \\
Egg producion $(\%)$
\end{tabular}

$\mathrm{P}<0,05$ = Significativo (Significant); $\mathrm{P}<0,01={ }^{* *}$ significativo (Significant).

Médias seguidas de diferentes letras na coluna diferem $(P<0,05)$ pelo teste Tukey.

Means followed by different letters in the column differ $(P<.05)$ by Tukey test.

R. Bras. Zootec., v.33, n.5, p.1197-1208, 2004 
apresentaram ganhos observados menores. Assim, os programas de alimentação segundo os modelos NRC (1994) e UNESP (2000) forneceram energia em excesso, resultando nas maiores diferenças entre os ganhos de peso previsto e observado.

Em se tratando de matrizes de corte, o ganho de peso elevado é indesejável, principalmente para aves com idade avançada, forte tendência à obesidade e aparecimento de ciclo erradico de produção, em função de maior acúmulo de gordura, que prejudica o desempenho reprodutivo.

Os dados apresentados na Tabela 7 mostram que a maior parte da energia consumida pelas aves submetidas aos programas de alimentação, com base nos modelos NRC (1994) e UNESP (2000), foi destinada à mantença, seguida das necessidades para produção de ovos e ganho de peso. Como o incremento da energia, proporcionado por essa estimativa, não resultou em aumento da produção, houve excesso de energia consumida desviada para ganho de peso e, certamente, depositada como gordura corporal. Dessa forma, os modelos promoveram superestimativas nas exigências de energia metabolizável.

Verifica-se que, segundo as estimativas do NRC (1994), os maiores percentuais de energia foram destinados à mantença (média de $82 \%$ ), quando comparado ao modelo UNESP (2000), média de $74 \%$, demonstrando os maiores fornecimento de energia proporcionado pelo NRC (2000), em função das altas estimativas nas exigências de mantença. Chwalibog et al. (1985) e Macleod \& Jewitt (1988) relatam que $65 \%$ da energia metabolizável ingerida são perdidos como calor e apenas $35 \%$ estão disponíveis para produção, proporções diferentes das encontradas neste experimento.

Leeson \& Summers (2000) comentam que, à medida que a ave envelhece, alteram-se as exigências reais de nutrientes e a distribuição dessas necessidades. Assim, com 55 semanas de idade, a matriz necessita de menos energia e proteína para produção de ovos que com 32 semanas. Embora o tamanho do ovo tenha aumentado, a produção declinou, mas exigiu maior quantidade de nutrientes para manutenção, uma vez que

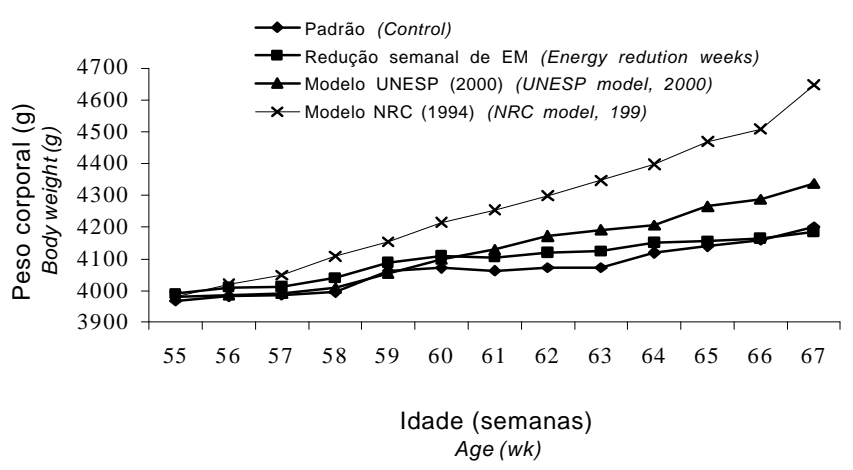

Figura 1 - Peso médio semanal de matrizes pesadas submetidas aos diferentes programas de alimentação de 55 a 66 semanas de idade.

Figure 1 - Weekly average body weight of broiler breeders submitted to different feeding programs from 55 to 66 weeks of age.

Tabela 5 - Peso médio (g) e ganho de peso ( $\mathrm{g}$ ) de matrizes pesadas submetidas a diferentes programas de alimentação, no período de 55 a 66 semanas de idade

Table 5 - Average weight and weight gain $(g)$ of broiler breeders, according to different feeding programs, from 55 to 66 weeks of age

\begin{tabular}{|c|c|c|c|}
\hline \multirow[t]{2}{*}{$\begin{array}{l}\text { Programas alimentares } \\
\text { Feeding programs }\end{array}$} & \multicolumn{2}{|c|}{$\begin{array}{l}\text { Peso corporal }(\mathrm{g}) \\
\text { Body weight }(\mathrm{g})\end{array}$} & \multirow[t]{2}{*}{$\begin{array}{c}\text { Ganho de peso } \\
\text { Weight gain }\end{array}$} \\
\hline & $\begin{array}{l}\text { Às } 55 \text { semanas } \\
\text { At } 55 \text { weeks }\end{array}$ & $\begin{array}{l}\text { Às } 66 \text { semanas } \\
\text { At } 66 \text { weeks }\end{array}$ & \\
\hline $\begin{array}{l}\text { Padrão } \\
\text { Control }\end{array}$ & $3.978 \pm 42$ & $4.207 \pm 24$ & $229 \pm 55^{b}$ \\
\hline $\begin{array}{l}\text { Redução de energia semanal } \\
\text { Weekly energy reduction }\end{array}$ & $4.033 \pm 56$ & $4.217 \pm 70$ & $181 \pm 62^{b}$ \\
\hline $\begin{array}{l}\text { Modelo UNESP (2000) } \\
\text { Model -UNESP (2000) }\end{array}$ & $3.984 \pm 36$ & $4.269 \pm 146$ & $285 \pm 128^{b}$ \\
\hline $\begin{array}{l}\text { Modelo NRC (1994) } \\
\text { Model-NRC (1994) }\end{array}$ & $4.035 \pm 34$ & $4.679 \pm 41$ & $644 \pm 57^{\mathrm{a}}$ \\
\hline
\end{tabular}

$\mathrm{CV}=23,99 \%, \mathrm{~F}=31,41$.

Médias seguidas de diferentes letras na coluna diferem $(P<0,05)$ pelo teste Tukey.

Means followed by different letters in the column differ $(P<.05)$ by Tukey test. 
a ave cresceu. Houve também redução na taxa de crescimento e conseqüente diminuição na necessidade de nutrientes para o crescimento. Todos esses eventos resultaram em menor exigência total de energia.

Neste experimento, com o avançar da idade, os valores de energia estimados pelos modelos para a produção diminuíram e para ganho se mantiveram constantes, ao passo que para mantença aumentaram na mesma proporção, reduzindo a estimativa para a produção. O resultado final foi aumento nas estimativas das exigências totais pelos modelos UNESP (2000) e NRC (1994).

No início do experimento, as aves pesavam em torno de $10 \%$ acima do recomendado pelo manual da linhagem. Além de proporcionar maior exigência de mantença, estavam com reservas corporais de energia, certamente na forma de gordura, o que pode ter influenciado os resultados experimentais.

A taxa metabólica do tecido gorduroso é menor que a de outros tecidos, mas este não é um tecido inerte. Então, com o avanço da idade, as exigências por unidade de peso metabólico podem ser alteradas, em decorrência de mudanças no peso e na composição química corporal das aves, principalmente pelo aumento na quantidade de gordura (Blaxter 1989). Por outro lado, ganho de peso em proteína nas aves mais jovens é relativamente superior ao das mais velhas, que têm maior ganho em gordura, modificando as

Tabela 6 - Médias reais e previstas de ganho de peso (g/ave/dia) e produção de massa de ovos (g) avaliadas semanalmente e durante cada período, e a diferença entre 0 estes valores obtidos nos tratamentos experimentais

Table 6 - Actual and estimated means of weight gain (g/bird/day) and egg mass production (g/bird/day) evaluated weekly and in each period, and the difference among these values from the experimental treatments

\begin{tabular}{|c|c|c|c|c|c|c|}
\hline \multirow{3}{*}{$\begin{array}{c}\text { Período } \\
\text { (semanas) } \\
\text { Period }(W k)\end{array}$} & \multicolumn{3}{|c|}{$\begin{array}{c}\text { Ganho de peso (g/ave/dia) } \\
\text { Weight gain(g/bird/day) }\end{array}$} & \multicolumn{3}{|c|}{$\begin{array}{c}\text { Massa de ovos (g/ave/dia) } \\
\text { Egg weight production (g/bird/day) }\end{array}$} \\
\hline & Previsto & Real & Diferença & Previsto & Real & Diferença \\
\hline & Estimated & Actual & Difference & Estimated & Actual & Difference \\
\hline \multicolumn{7}{|c|}{$\begin{array}{c}\text { Padrão da linhagem } \\
\text { Control }\end{array}$} \\
\hline $55-58$ & 0,70 & 3,41 & 2,71 & 46,49 & 47,24 & 0,75 \\
\hline $59-62$ & 0,76 & 0,35 & $-0,41$ & 43,75 & 43,70 & $-0,05$ \\
\hline $63-66$ & 0,72 & 4,54 & 3,82 & 41,67 & 42,09 & 0,42 \\
\hline $\begin{array}{l}\text { Médias } \\
\text { Means }\end{array}$ & 0,73 & 2,76 & 2,03 & 43,97 & 44,34 & 0.37 \\
\hline \multicolumn{7}{|c|}{$\begin{array}{c}\text { Redução de energia semanal } \\
\text { Weekly energy redution }\end{array}$} \\
\hline $55-58$ & 0,57 & 2,20 & 1,63 & 45,27 & 45,94 & 0,67 \\
\hline $59-62$ & 0,61 & 0,36 & $-0,25$ & 44,43 & 42,98 & $-1,45$ \\
\hline $63-66$ & 0,61 & 2,62 & 2,01 & 40,90 & 41,02 & 0,12 \\
\hline $\begin{array}{l}\text { Médias } \\
\text { Means }\end{array}$ & 0,60 & 1,72 & 1,12 & 43,53 & 43,31 & $-0,22$ \\
\hline \multicolumn{7}{|c|}{$\begin{array}{l}\text { Equação UNESP (2000) } \\
\text { Model -UNESP (2000) }\end{array}$} \\
\hline $55-58$ & 0,70 & 2,70 & 2,00 & 46,11 & 47,09 & 0,97 \\
\hline $59-62$ & 0,76 & 4,83 & 4,07 & 43,59 & 42,96 & $-0,63$ \\
\hline $63-66$ & 0,74 & 5,25 & 4,51 & 40,73 & 41,58 & 0,85 \\
\hline $\begin{array}{l}\text { Médias } \\
\text { Means }\end{array}$ & 0,73 & 4,26 & 3,53 & 43,48 & 43,88 & 0,40 \\
\hline \multicolumn{7}{|c|}{$\begin{array}{c}\text { Equação NRC(1994) } \\
\text { Model-NRC(1994) }\end{array}$} \\
\hline $55-58$ & 0,71 & 6,16 & 5,44 & 44,80 & 45,19 & 0,39 \\
\hline $59-62$ & 0,78 & 6,84 & 6,06 & 43,38 & 43,16 & $-0,22$ \\
\hline 63-66 & 0,77 & 10,77 & 10,00 & 39,96 & 40,22 & 0,27 \\
\hline $\begin{array}{l}\text { Médias } \\
\text { Means }\end{array}$ & 0,75 & 7,92 & 7,17 & 42,71 & 42,86 & 0,15 \\
\hline
\end{tabular}

R. Bras. Zootec., v.33, n.5, p.1197-1208, 2004 
eficiências de utilização de energia para o ganho de peso, pois existem diferenças nas eficiências de retenção da energia como proteína e gordura, que foram superiores para deposição de gordura (Macleod, 1990; Nieto et al., 1995).

Fatores como idade da ave e peso excessivo com acúmulo de tecido gorduroso também podem acarretar menor locomoção e maior capacidade da ave em reter o calor corporal, modificando as exigências de energia para mantença. Alguns pesquisadores têm demonstrado que os efeitos do exercício físico levam a diferenças em gastos energéticos (Morse \& Smith, 1972; Van Kampen, 1976; Boshouwers \& Nicaise, 1983; Mcleod et al., 1982; Boshouwers \& Nicaise, 1985; Li et al., 1991).

Conforme abordado anteriormente, o modelo da UNESP (2000) foi determinado em aves mais jovens, com peso e composição corporal diferentes das aves após 55 semanas de idade. É possível que as exigências de energia para mantença e ganho de peso preconizadas por esse modelo tenham contribuído para as superestimativas nas exigências totais de energia metabolizável para as matrizes no período de 55 a 66 semanas de idade.

Apesar de recomendado para aves em produção, o modelo do NRC (1994) foi elaborado a partir de dados de experimentos realizados com aves produtoras de ovos para consumo. Certamente, essas aves apresentam comportamento diferenciado quanto às exigências nutricionais, em relação às matrizes pesadas. Diversos trabalhos (Waring \& Brown, 1965 e 1967; Grimbergen, 1974; Basaglia, 1999; Rabello et al., 2000a) demonstram diferenças nas exigências de energia para mantença, quando foram comparadas aves leves, semi-pesadas e pesadas, observando-se os maiores valores para as aves mais leves. Este resultado levou à maior estimativa das exigências energéticas para as matrizes após 55 semanas de idade, com o modelo do NRC (1994).

Os resultados de desempenho reprodutivo são apresentados na Tabela 8. Observa-se que não houve efeito significativo dos programas de alimentação sobre a taxa de eclosão e fertilidade dos ovos. Entretanto, a taxa de eclodibilidade e o peso dos pintos ao nascimento foram influenciados pelos tratamentos.

O programa de alimentação de acordo com o modelo NRC (1994) apresentou menor percentual de eclodibilidade. A explicação para este resultado está relacionadaà maior mortalidade embrionária durante o período de incubação, o que certamente acarretou diminuição da eclodibilidade. Wilson (1991) relatou que ovos grandes têm maior susceptibilidade à quebra e contaminação, o que pode reduzir a eclodibilidade. Por outro lado, fêmeas obesas possuem tendência em produzir ovos que apresentam maior mortalidade embrionária (Lewis, 1996).

Tabela 7 - Partição da energia total (kcal EM/ave/dia) em ingerida para mantença, ganho de peso e produção

Table 7 - Partition of total energy (kcal ME/bird/day) into maintenance, weight gain and egg production ME requirements

\begin{tabular}{|c|c|c|c|c|c|c|c|c|}
\hline \multicolumn{9}{|c|}{$\begin{array}{c}\text { Partição de energia metabolizável ingerida } \\
\text { Partition of } M E \text { intake }\end{array}$} \\
\hline \multirow[t]{2}{*}{$\begin{array}{l}\text { Período } \\
\text { Period }\end{array}$} & \multirow[t]{2}{*}{$\begin{array}{l}\text { Idade } \\
\text { Age }\end{array}$} & \multicolumn{4}{|c|}{$\begin{array}{l}\text { (kcal/ave/dia) } \\
\text { kcal ME/bird/day }\end{array}$} & \multicolumn{3}{|c|}{$(\%)$} \\
\hline & & $\begin{array}{l}\text { Mantença } \\
\text { Maintenance }\end{array}$ & $\begin{array}{c}\text { Ganho } \\
\text { Weight } \\
\text { gain }\end{array}$ & $\begin{array}{l}\text { Produção } \\
\text { Production }\end{array}$ & $\begin{array}{l}\text { Total } \\
\text { Total }\end{array}$ & $\begin{array}{l}\text { Mantença } \\
\text { Maintenance }\end{array}$ & $\begin{array}{c}\text { Ganho } \\
\text { Weight } \\
\text { gain }\end{array}$ & $\begin{array}{l}\text { Produção } \\
\text { Production }\end{array}$ \\
\hline \multicolumn{9}{|c|}{$\begin{array}{l}\text { Modelo UNESP (2000) } \\
\text { Model - UNESP (2000) }\end{array}$} \\
\hline 1 & $55-58$ & 315,62 & 4,32 & 112,41 & 432,35 & 73 & 1 & 26 \\
\hline 2 & $59-62$ & 335,46 & 4,47 & 107,35 & 447,28 & 75 & 1 & 24 \\
\hline 3 & $63-66$ & 345,70 & 4,49 & 98,77 & 448,97 & 77 & 1 & 22 \\
\hline \multicolumn{9}{|c|}{$\begin{array}{l}\text { Modelo do NRC (1994) } \\
\text { Model - NRC (1994) }\end{array}$} \\
\hline 1 & $55-58$ & 370,46 & 4,63 & 87,98 & 463,08 & 80 & 1 & 19 \\
\hline 2 & $59-62$ & 397,05 & 4,90 & 88,23 & 490,19 & 81 & 1 & 18 \\
\hline 3 & $63-66$ & 413,95 & 4,99 & 79,80 & 498,73 & 83 & 1 & 16 \\
\hline
\end{tabular}

R. Bras. Zootec., v.33, n.5, p.1197-1208, 2004 
Tabela 8 - Eclosão (\%), eclodibilidade (\%), fertilidade (\%) e pesos médios dos pintos ao nascimento (g) e dos ovos incubados $(\mathrm{g})$, obtidos de matrizes pesadas com 63 semanas, submetidas a diferentes programas de alimentação

Table 8 - Hatching (\%), eclodibility (\%), fertility (\%), chick weight $(g)$ and egg weight $(g)$ for 63-wk old broiler breeders, according to the different feeding programs

\begin{tabular}{|c|c|c|c|c|c|}
\hline $\begin{array}{l}\text { Programas alimentares } \\
\text { Feeding programs }\end{array}$ & $\begin{array}{c}\text { Eclosão (\%) } \\
\text { Hatching } \\
\text { egg }\end{array}$ & $\begin{array}{l}\text { Eclodibilidade (\%) } \\
\text { Eclodibility }\end{array}$ & $\begin{array}{c}\text { Fertilidade }(\%) \\
\text { Fertility }\end{array}$ & $\begin{array}{l}\text { Peso dos pintos }(\mathrm{g}) \\
\text { Chick weight }\end{array}$ & $\begin{array}{l}\text { Peso dos ovos (g) } \\
\text { Egg weight }\end{array}$ \\
\hline $\begin{array}{l}\text { Padrão } \\
\text { Control }\end{array}$ & 87,97 & $92,59^{a b}$ & 95,00 & $50,40^{b}$ & $70,53^{a}$ \\
\hline $\begin{array}{l}\text { Redução de energia semanal } \\
\text { Weekly energy reduction }\end{array}$ & 88,41 & $94,41^{\mathrm{a}}$ & 93,61 & $50,82^{a b}$ & $70,63^{a}$ \\
\hline $\begin{array}{l}\text { Modelo UNESP (2000) } \\
\text { Model-UNESP (2000) }\end{array}$ & 87,08 & $93,98^{\mathrm{a}}$ & 92,55 & $50,07^{b}$ & $70,08^{a}$ \\
\hline $\begin{array}{l}\text { Modelo NRC (1994) } \\
\text { Model-NRC (1994) }\end{array}$ & 83,14 & $89,99^{\mathrm{b}}$ & 92,38 & $51,69^{\mathrm{a}}$ & $71,29^{\mathrm{a}}$ \\
\hline $\begin{array}{l}\overline{\mathrm{CV}(\%)} \\
\mathrm{F}\end{array}$ & $\begin{array}{l}5,95 \\
1,05^{\mathrm{ns}}\end{array}$ & $\begin{array}{l}2,42 \\
3,76^{*}\end{array}$ & $\begin{array}{l}4,26 \\
0,46^{\mathrm{ns}}\end{array}$ & $\begin{array}{l}1,39 \\
4,93^{*}\end{array}$ & $\begin{array}{l}1,14 \\
1,90^{\mathrm{ns}}\end{array}$ \\
\hline
\end{tabular}

NS = não significativo (Not significant), ${ }^{*}=$ Significativo (Significant) $\mathrm{P}<0,05$, ** significativo (Significant) $\mathrm{P}<0,01$.

Médias seguidas de diferentes letras na coluna diferem $(P<0,05)$ pelo teste Tukey.

Means followed by different letters in the column differ $(P<.05)$ by Tukey test.

O peso dos pintos das aves alimentadas segundo o modelo NRC (1994) foi significativamente maior. Apesar de não ter sido observada diferença significativa para o peso dos ovos incubados, os ovos dessas aves foram numericamente mais pesados, o que talvez possa explicar o maior peso dos pintos desse tratamento. Segundo Wilson (1991) e Argenta et al. (2001), vários autores relatam a alta e positiva correlação entre peso do ovo e tamanho do pinto. Normalmente, o peso do pinto ao nascer varia de 62 a $76 \%$ do peso do ovo e as variações no peso do pinto decorrem de diferenças no peso do ovo fresco, perda de peso durante a incubação, peso da casca e outros resíduos no nascimento. Neste experimento, o peso do pinto correspondeu a 71,46; 71,95; 71,45 e 72,51\% do peso do ovo para as aves submetidas aos programas padrão, redução de energia, modelos UNESP (2000) e NRC (1994), respectivamente.

\section{Conclusões}

O programa de alimentação com redução semanal de energia foi adequado para manter os desempenhos produtivo e reprodutivo das matrizes.

O programa de alimentação de acordo com os modelos UNESP (2000) e NRC (1994) proporcionaram estimativas mais elevadas das exigências energéticas que o modelo padrão e o modelo com redução de $2 \mathrm{kcal} / \mathrm{ave} /$ dia por semana, para matrizes a partir de 55 semanas de idade.

\section{Literatura Citada}

ARGENTA, J.A.; SAKOMURA, N.K.; AZEVEDO JR., P.C. Avaliação de programas de alimentação para matrizes de corte na fase de produção. Revista Brasileira de Zootecnia, v.30, n.6, p.1735-1741, 2001.

ATTIA,Y.A.; BURKE, W.H.; YAMANA, K.A. et al. Daily energy allotments and reproductive performance of broiler breeders. 2. Females. Poultry Science, v.72, p.247-260, 1995.

BASAGLIA, R. Modelos de predição das exigências das exigências de energia e proteína para poedeiras leves. Jaboticabal: Universidade Estadual Paulista, 1999. 158p. Tese (Doutorado em Zootecnia) - Universidade Estadual Paulista, 1999.

BLAIR, R.; MAGGOWAN, M.M.; BOLTON, W. Effects of food regulation during the growing and laying stages on the producvity of broiler breeders. British Poultry Science, v.17, p.215-223,1976.

BLAXTER, K. Energy metabolism in animal and man. Cambridge: Cambridge University Press, 1989. 336p.

BORNSTEIN, S.; HURWITZ, S.; LEV, Y. The amino acid and energy requirements of broiler breeder hens. Poultry Science, v.58, n.1, p.104-116, 1979.

BOSHOUWERS, F.M.G.; NICAISE, E. Automatic gravimetric calorimeter with simultaneous recording of phisycal activity for poultry. British Poultry Science, v.26, p.534-541, 1985.

BOSHOUWERS, F.M.G.; NICAISE, E. The respiration quotient in indirect calorimetric measurements. British Poultry Science, v.24, p.273-279, 1983.

CHANEY, L.W.; FULLER, H.L. The relation of obesity to egg production in broiler breeders. Poultry Science, v.54, p.200-207, 1975.

CHWALIBOG, A. Studies on energy metabolism in laying hens. Denmark: National Institute of Animal Science, 1985. p.509-515 (Report, n.578).

GRIMBERGEN, A.H.M. Energy expenditure under prodctive conditions. In: MORRIS, T.R.; FREEMAN, B.M. (Eds.). Energy requirements of poultry. Edinburgh: British Poultry Science, 1974. p.61-71. 
KUANA, S. Exigências nutricionais de energia metabolizável + cistina e de lisina para matrizes pesadas. Viçosa, MG: Universidade Federal de Viçosa, 1986. 67p. Dissertação (Mestrado em Zootecnia) - Universidade Federal de Viçosa, 1986.

LEESON, S.; SUMMERS,J.D. Broiler breeder production. 1.ed. Guelph: University Books, 2000. 329p.

LEESON, S.; SUMMERS, J.D. Commercial Poultry Nutrition. 2 ed. Guelph: University Books, 1997. 355p.

LI, Y.; ITO, T.; YANAMOTO, S. Diurnal variation of heat production relatede to some physical activities in laying hens. British Poultry Science, v.32, n. 4, p. 821-827,1991.

MACDANIEL, G.R.; BRAKE, J.; ECKMAN, M.K. Factors affecting broiler breeder performance. The interrelationship of some reproductive traits. Bristish Poultry Science, v.17,p.215-223,1981.

MACLEOD, M.G.; JEWITT, T.R. Maintenance energy requirements of laying hens a comparison of measurements made by two methods based on indirect calorimetry. British Poultry Science, v.29, p.63-74, 1988.

MACLEOD, M.G.; JEWITT, T.R.; WHITE, J. et al. The contribution of locomotor activity to energy expenditure in the dosmestic fowl. In: EKERN, A.; SUNDSTOL, F. (Eds.). Energy metabolism of farm animal. Norway: The Agricultural University of Norway, 1982. p.297-300.

MACLEOD, M.G. Energy and nitrogen intake, expenditure and retention at $20^{\circ}$ in growing fowl given diets with a wide range of energy and protein contents. British Journal Nutrition, v.64, n.3, p.625-637, 1990.

MORSE, J.T. ; SMITH, A.H. Exercise capacity in a population of domestic fowl: effects of selection and training. American Journal of phisiology, v.222, p.1380-1385, 1972.

NATIONAL RESEARCH COUNCIL - NRC. Committee on Animal Nutrition. Subcommittee on Poultry Nutrition. Nutrient requeriments of poultry. 9.ed. Washington: National Academy of Sciences, 1994. 155p.

NIETO, R.; PRIETO, C.; FERNANDEZ-FÍGARES, I. et al. Effect of dietary protein quality on energy metabolism in growing chickens. British Poultry Science, v.74, p.163-172, 1995.

PEARSON, R.A.; HERRON, K.M. Effects of energy and protein allowance during lay on the reproductive performance of broiler breeder. British Poutry Science, v.22, n.2, p.227-239, 1981.

PEARSON, R.A.; HERRON, K.M. Effects of maternal energy and protein intakes on the incidence of malformations and time of death during incubation. British Poutry Science, v.23, p.71-77, 1982b.
PYM, R.A.E.; BRAKE, J.F. Restricted food intake and reproductive performance of broiler breeder pullets. British Poutry Science, v.15, p245-259, 1974.

RABELLO, C.B.V.; SAKOMURA, N.K.; PACHECO, C.R. et al. Alimentação de reprodutoras pesadas utilizando modelo de predição das exigências de energia. Revista Brasileira de Ciência Avícola, supl 2, p.12, 2000b.

RABELlO, C.B.V.; SAKOMURA, N.K.; PACHECO, C.R. et al. Modelo de predição das exigências de energia metabolizável para matrizes pesadas na fase de produção. Revista Brasileira de Ciência Avícola, supl. 2, p.11, 2000a.

SAKOMURA, N.K. ; ROSTAGNO, H.S.; EUCLYDES, R.F. et al. Alimentação de matrizes pesadas, utilizando modelos para determinar a exigência de energia metabnolizável. Revista da Sociedade Brasileira de Zootecnia, v.24, n.4, p.570-589, 1995.

SAKOMURA, N.K.; ROSTAGNO, H.S.; FONSECA, J.B. Determinação das equações de predição da exigência nutricional de energia para matrizes pesadas e galinhas poedeiras. Revista da Sociedade Brasileira de Zootecnia, v.22, n.5, p.723-731, 1993.

STATISTICAL ANALYSES SYSTEM - SAS. User's guide: statistics. version 6. 12.ed. Cary: 1996.

SPRATT, R.S.; LEESON, S. Broiler breeder performance in response to diet protein and energy. Poultry Science, v.66, p.683-693, 1987.

Van KAMPEN, M. Activity and energy expenditure in laying hens: 1 . The energy cost of nesting activity and oviposition. Journal Agriculture Science, v.86, n.2, p.471-473,1976.

WALDROUP, P.W.; HAZEN, K.R.; BUSSEL, W.D. et al. Studies on the daily protein and amino acid needs of broiler breeder hens. Poultry Science, v.55, n.9, p.2342-2347, 1976.

WARING, J.J. ; BROWN, W.O. A respiration chamber for the study of energy utilisation for maintenance and production in the laying hen. Journal Agricultural Science, v.68, p.139-146, 1965.

WARING, J.J.; BROWN, W.O. Calorimetric studies on the utilization of dietary energy by the laying white leghorn hens in relation of plane of nutrition and environmental temperature. Journal Agricultural Science, v.68, n.1, p.149-155, 1967.

WILSON, H.R. Interrelationships of eggs size, chick size, posthatching growth and hatchability. World's Poultry Science Journal, v.47, n.1, p.5-20, 1991.

Recebido em: 11/12/02

Aceito em: 04/11/03 